\title{
New tangles in the auxin signaling web
}

\section{R.Clay Wright and Jennifer L. Nemhauser*}

\author{
Address: Department of Biology, University of Washington, Seattle, Washington 98195, USA \\ *Corresponding author: Jennifer L. Nemhauser (jn7@uw.edu) \\ Fl000Prime Reports 2015, 7:19 (doi:10.12703/P7-19) \\ All Fl000Prime Reports articles are distributed under the terms of the Creative Commons Attribution-Non Commercial License \\ (http://creativecommons.org/licenses/by-nc/3.0/legalcode), which permits non-commercial use, distribution, and reproduction in any medium, \\ provided the original work is properly cited. \\ The electronic version of this article is the complete one and can be found at: http://fl000.com/prime/reports/b/7/19
}

\begin{abstract}
Plants use auxin to relay critical information that shapes their growth and development. Auxin perception and transcriptional activation are mediated by the degradation of Aux/IAA repressor proteins. Degradation of Aux/IAAs relieves repression on Auxin Response Factors (ARFs), which bind DNA sequences called Auxin Response Elements (AuxREs). In most higher plant genomes, multiple paralogs exist for each part of the auxin nuclear signaling pathway. This potential combinatorial diversity in signaling pathways likely contributes to the myriad of context-specific responses to auxin. Recent structures of several domains from ARF proteins have exposed new modes of ARF dimerization, new models for ARF-AuxRE specificity, and the strong likelihood of larger order complexes formed by ARF and Aux/IAA homo- and heteromultimerization. Preliminary experiments support a role for these novel interactions in planta, further increasing the potential architectural complexity of this seemingly simple pathway.
\end{abstract}

\section{Introduction}

Auxin signaling affects many vital transitions in the development of plants found throughout the green plant lineage [1]. Many of the proteins involved in converting environmental signals into auxin gradients [2-5] and translating these internal signals into growth responses [6-14] have been identified and characterized. In the past several decades, the plant biology community has made great strides in structure-function analysis of auxin signaling [15]. More recent advances have quantified interactions and dynamics within the pathway in an attempt to answer the question of how auxin mediates such a variety of responses (e.g. [16-19]). The auxin-signaling pathway has been reviewed many times in recent years [20-24] and will only be described briefly here. This review will focus on a suite of recent structural studies [25-27] that significantly revise models of auxin response.

The forward nuclear auxin signaling pathway can be reconstituted in yeast using only five plant parts [28], providing strong evidence that this circuit represents the minimal auxin-specific response machinery. These parts include ARFs, which are able to bind to promoters containing AuxREs [6,7]. In the absence of auxin, ARFs are bound to Aux/IAA repressor proteins (Figure 1B) [8]. Repression by Aux/IAAs is facilitated by recruitment of TOPLESS-type corepressors (TPLs) [29]. Auxin relieves ARFs of this repression by enhancing associations between Aux/IAAs and members of the TIR1/AFB family of auxin receptors [12]. TIR1/AFBs act as the substrate recognition subunit of Skp1-Cullin-F-box E3 ubiquitin-ligase complexes. Thus, auxin promotes ubiquitination and subsequent degradation of Aux/IAAs, relieving transcriptional repression on auxin response genes $[13,14]$. The mechanism by which ARFs mediate transcriptional activation is not well understood.

The Arabidopsis thaliana genome contains 6 TIR1/AFBs [30], 29 Aux/IAAs [31], 23 ARFs [32] and 5 TPLs [29]. Each of these family members offers potential for specificity in function, dynamics and localization. TIR1/AFBs and Aux/IAAs are known to form complexes of varying affinity with auxin analogs [17] and result in different degradation rates [16]. Subfunctionalization within the TIR1/AFB, Aux/IAA and ARF families through distinct expression patterns is supported by recent detailed studies of the shoot apical meristem, embryo, and root meristem [18,33]. 
Recent structural studies of isolated domains from ARF proteins have exposed additional potential for signaling complexity. Specifically, the structures of two ARF DNAbinding domain (DBD) dimers were solved [25], as well as two ARF C-terminal III/IV or PB1 domains [26,27]. PB1 domains are also found in Aux/IAAs [34]. The structures and accompanying experiments provide new models for specificity in ARF-AuxRE interactions and reveal the possibility of higher order complexes of ARFs and Aux/IAAs. Connecting signaling architectures to specific cellular responses is the next major challenge.

\section{ARFs and their targets, AuxREs}

Most ARFs contain three domains with distinct functions [35] (Figure 1A). All ARFs contain an N-terminal DNAbinding domain (DBD) related to the B3 domain family. B3 domains are found in many other plant transcription factors [36], but the regions $5^{\prime}$ and $3^{\prime}$ of the $\mathrm{B} 3$ domain are unique to ARFs and are highly conserved across the family. The DBD is followed by a middle domain mediating transcriptional repression or activation [37], and a C-terminal PB1 protein-protein interaction domain [38]. In 2014, Boer et al. published structures of the Arabidopsis ARF1 and ARF5 DBDs, revealing that the non-B3 portions of the DBDs contain a dimerization interface without any matches to known structures [25]. The authors also briefly mention an additional subdomain of the ARF DBD, the ancillary domain, which is structurally related to Tudor domains. Tudor domains of many proteins have been shown to bind methylated histones [39]; however, ARF Tudor domains lack the methyl-binding site. Given the evidence of a connection between auxin and chromatin modification [40-43], further functional analysis of this domain could be important for elucidating the mechanism of ARF transcriptional activation.

In addition to the structures of ARF1 and ARF5 DBDs, Boer $e$ al. present the crystal structure of an ARF1 DBD dimer in complex with an inverted repeat (3' ends facing

Figure I. Domain diagram and simple structural schematic of the newly postulated auxin responsive transcriptional regulatory complex

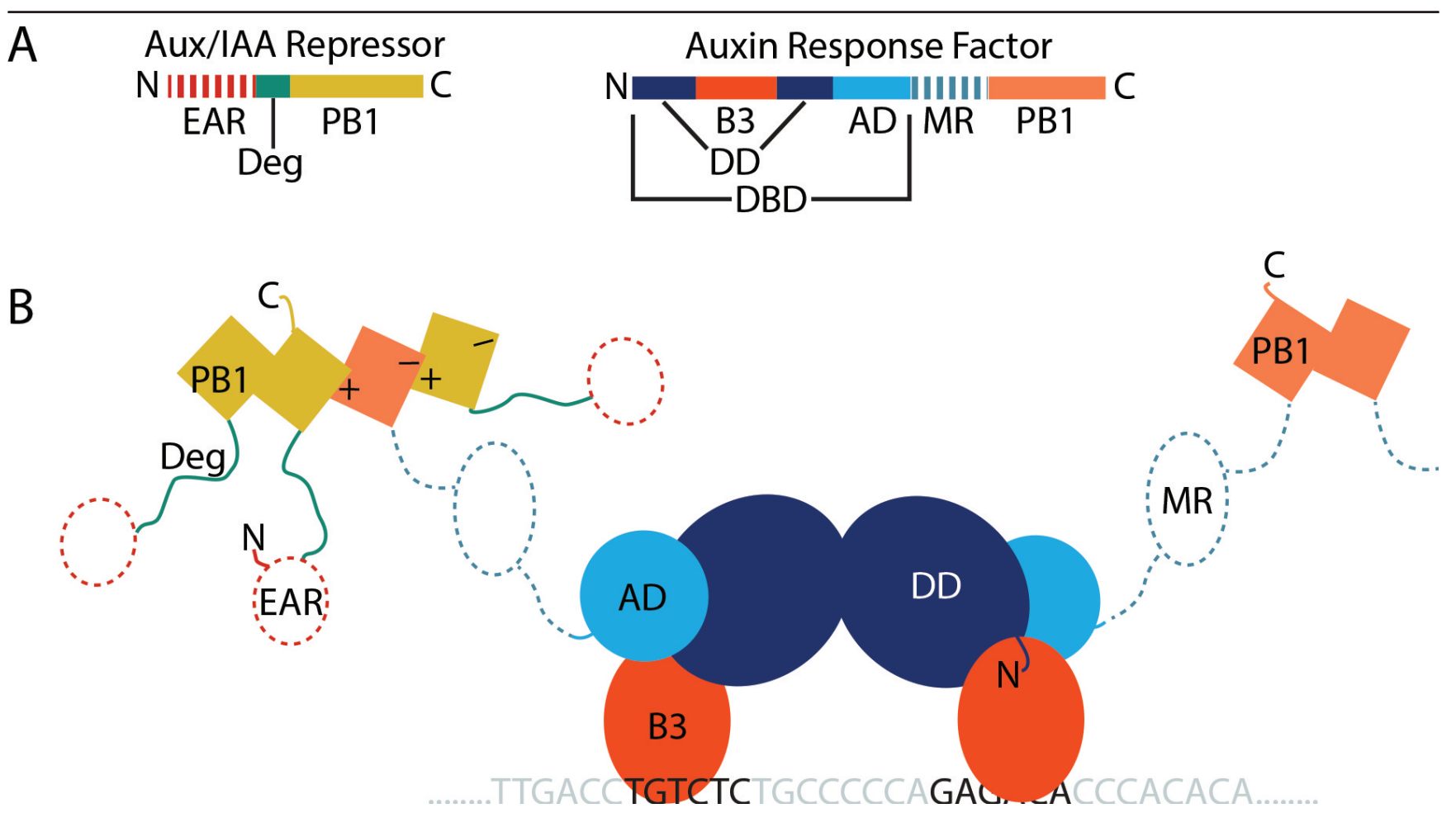

(A) Domain diagrams of a typical Aux/IAA repressor family protein and a typical Auxin Response Factor (ARF) transcription factor. (B) A highly simplified structural schematic of an ARF regulatory complex in the absence of auxin. An ARF dimer is bound to an Auxin Response Element (AuxRE) inverted repeat. $A R F$ and Aux/IAA PBI domains form multimers, interacting via positive and negative faces. Structural data exist for domains with solid colors and lines, whereas dashed lines represent domains of unknown structure.

DBD, DNA-binding domain, DD, dimerization domain; B3, B3 DNA-binding domain; AD, ancillary domain; MR, middle region; PBI, PBI protein-protein interaction domain; EAR, EAR motif corepressor-binding domain; Deg, degron motif; N, N-terminus; C, C-terminus. 
inward) of AuxREs [25]. These structures and accompanying experiments reveal that DBDs mediate ARF-ARF interactions in ARF homodimers and present strong evidence for the necessity of ARF DBD dimerization for transcriptional activation. Evidence for PB1-domainindependent ARF dimerization can be traced to the earliest days of biochemical characterization of this family [10]; however, the strong effect of the PB1 dimerization domain and its connection to the Aux/IAAs overshadowed these early results. FRET-FLIM assays using wild-type and mutant forms of ARF5 confirm dimer formation in the native context. The functional importance of ARF5 DBD dimerization was demonstrated by overexpressing a dimerization-defective variant in either loss-of-function arf $5 / m p$ mutants or in wild-type plants. The mutant form of ARF5 could not rescue the deficiency in arf5/mp mutants and, in fact, acted as a dominant-negative in the wild-type background. The residues involved in dimerization are highly conserved across ARFs, but whether ARF DBD dimerization is necessary for activating all target genes, or for the function of all ARFs, remains to be determined.

The Boer et al. paper [25] also provided some surprises about the sequence of AuxREs and ARF-AuxRE specificity. Microarray experiments saturating for all hexanucleotides found that both ARF1 and ARF5 monomers prefer TGTCGG to the "canonical" AuxRE TGTCTC [6,7], although this sequence was also bound strongly by ARFs in this experiment. Broad sequence-specificity was observed for both ARFs at the final two bases, consistent with previous suggestions that the core TGTC sequence might be sufficient to confer auxin-responsiveness $[10,44]$. Dimerization-defective mutants showed nearly identical binding specificity, demonstrating independence of the dimer and DNA binding faces of the protein. These mutants did show significantly lower affinity for inverted repeat AuxREs, demonstrating a loss of cooperative binding effects. As the DNA binding residues of ARFs are highly conserved and the most sequence divergence occurs in loops connecting the $\mathrm{B} 3$ and dimerization domains, the authors hypothesize that ARF dimers act as "molecular calipers" with distinct settings established by their specific DBDs. A particular DBD dimer would show specificity for certain promoter architecture, as the loops within the DBD would limit how far the dimer can stretch between adjacent AuxREs. To test this hypothesis, ARF1 and ARF5 dimers were exposed to synthetic promoters with TGTCTC elements separated by between 5 and 9 nucleotides. ARF1 bound most strongly to promoters with AuxREs separated by 7 or 8 bases, with a sharp decrease in binding capacity for variants outside this range. In contrast, ARF5 displayed a much broader binding profile, retaining relatively high affinity for all promoter architectures tested. Many highly auxin responsive promoters contain multiple AuxREs [44], although a large number of auxin responsive genes do not have AuxREs in tandem arrangements like the ones tested here. How ARF dimerization and promoter specificity facilitate interaction and integration with other transcription factors [45-47] also remains an area for future investigation.

\section{ARFs and their repressors, Aux/IAAs}

Structural and biochemical studies of the PB1 domains of ARFs and Aux/IAAs raise new questions about the functional stoichiometry of auxin signaling $[26,27]$. Most Aux/IAAs have three recognizable domains (Figure 1A): an $\mathrm{N}$-terminal EAR-motif (domain I), which interacts with the TPL corepressors; a short degron domain (domain II) required for interaction with auxin and TIR1/AFBs; and a C-terminal PB1 domain (domain III/IV) that facilitates interaction with ARFs [31]. Multimerization of ARFs and Aux/IAAs through the C-terminal domain has long been recognized [48]. Recently, plant PB1 domains were found to share significant sequence homology with PB1 domains found to mediate multimerization in many other eukaryotic signaling proteins [34].

Recognition of the III/IV domains as PB1 folds led to critical technical insights for improving expression and purification-insights that led to recent structural studies of PB1 domains from ARF7 [26] and ARF5 [27]. Isolated PB1 domains form multimers in solution, interacting in a way analogous to bar magnets, via a positively charged face on one "pole", and a negatively charged face on the opposite "pole" (Figure 1B). The positive face contains a conserved lysine and the negative face contains a conserved acidic OPCA motif (D-x-D/E-x-D- $x_{n}-D / E$ ). These faces are highly conserved across most ARFs and Aux/IAAs, suggesting numerous potential combinations of homo- and heteromultimers. When conserved residues were mutated, on each face independently or on both faces, multimerization was highly abrogated. When mixing ARF7 proteins mutated on opposite faces, multimerization was inhibited and only dimers were observed [26]. This independence of the two faces (i.e. disrupting interactions on one face still leaves the opposite face functional) was further confirmed for both ARF5 and ARF7 by yeast two-hybrid assays $[26,27]$.

Preliminary plant studies support an important role for PB1 domain multimerization in auxin signaling. The strong growth defects that result from overexpression of a stabilized form of IAA16 [49] were essentially eliminated, if mutations that eliminated dimerization on either face were also included in the transgene [26]. Mutations on 
either side of the ARF7 PB1 domain led to a nearly twofold increase in auxin-induced expression of a reporter in protoplasts, when compared with wild-type ARF7 [27]. This reporter activation was also largely auxin-independent, although the effect of auxin could not be completely eliminated even when both interaction surfaces were mutated. Single face mutants of IAA17 and IAA19 were able to partially repress the reporter in protoplasts, while double face mutants showed a further reduction in repression ability. It will be exciting to see what emerges from detailed examination of component configuration on specific promoters during normal auxin responses.

\section{Untangling}

We have entered a new era in studies of auxin signaling. New models are needed to integrate structural knowledge with the rich history of molecular genetics and genomics connecting auxin nuclear signaling to plant growth and development. If higher order complexes containing various isoforms of ARFs and Aux/IAAs do exist in plants, do they have distinct functions? Answering that question will require significant work, likely drawing on the newest technologies in systems and synthetic biology. Current $[18,50]$ and future interactome studies provide a starting place for simplifying this complex network. Interactions can then be distilled to minimal functional units using existing synthetic systems $[16,17,28,51,52]$. Revisiting bioinformatics studies of auxin response genes [6] may help to establish tissueor timing-specific consensus sequences that can then be used to pull-down and identify the complexes responsible for mediating these processes. Additionally, many new tools for isolating tissue specific chromatin-state [53], methylation-state [54], expression [55] and transcription factor binding [50] information may prove useful in connecting auxin network structure to biochemical mechanisms and function.

As ARFs and Aux/IAAs belong to ancient lineages, it may prove advantageous to move to simpler model organisms to answer some of these pressing questions. The moss Physcomitrella patens $[56,57]$ and the liverwort Marchantia polymorpha [58-60] are quickly developing as attractive models. These organisms can perform homologous recombination $[61,62]$, facilitating rapid genome engineering. For example, reporter genes could be integrated under native promoters to directly connect the impact of multimerization mutants with a diverse set of realistically complex promoter architectures during native auxin responses. This type of gene replacement experiment could be very powerful, especially in genomes with far smaller families of auxin-related genes.
Even given the simplest repressive complex now proposed-two ARFs, two Aux/IAAs and a single corepressor-there are well over one million potential combinations of complexes. Moving forward, we will need to identify the subset of these possible complexes present in planta and understand the stoichiometry, configuration, functional specificity and dynamics of these activating or repressing complexes. These insights will have to be further integrated into models that include other regulatory mechanisms impacting auxin availability and response $[63,64]$. Despite adding new tangles to the auxin-signaling web, these unexpected levels of complexity may be the key to finally connecting the core auxin signaling circuit to the many distinct auxin-associated events throughout the life of the plant.

\section{Abbreviations}

ARF, Auxin Response Factor; AuxRE, Auxin Response Element; DBD, DNA-binding domain; TPL, TOPLESStype corepressor.

\section{Disclosures}

Work in the Nemhauser Lab on auxin is supported by grants from the Paul G. Allen Family Foundation, the National Institute of Health (1R01GM107084-01), and the National Science Foundation (MCB-1411949 to JLN and DBI-1402222 to RCW). Any opinions, conclusions or recommendations expressed in this material are those of the authors and do not necessarily reflect the views of the funding agencies.

\section{Acknowledgments}

The authors would like to thank Britney Moss and Edith Pierre-Jerome for helpful discussions and critical review of the manuscript.

\section{References}

I. De Smet I, Voss U, Lau S, Wilson M, Shao N, Timme RE, Swarup R, Kerr I, Hodgman C, Bock R, Bennett M, Jürgens G, Beeckman T: Unraveling the evolution of auxin signaling. Plant Physiol 20I I, I 55:209-2I.

2. Pickett FB, Wilson AK, Estelle M: The auxl Mutation of Arabidopsis Confers Both Auxin and Ethylene Resistance. Plant Physiol 1990, 94:1462-6.

3. Marchant A, Kargul J, May ST, Muller P, Delbarre A, PerrotRechenmann C, Bennett MJ: AUXI regulates root gravitropism in Arabidopsis by facilitating auxin uptake within root apical tissues. EMBO J 1999, 18:2066-73.

4. Friml J, Vieten A, Sauer M, Weijers D, Schwarz H, Hamann T, Offringa R, Jürgens G: Efflux-dependent auxin gradients establish the apical-basal axis of Arabidopsis. Nature 2003, 426:147-53.

\section{FlOOOPrime} RECOMMENDED

5. Petrásek J, Mravec J, Bouchard R, Blakeslee J], Abas M, Seifertová D, Wisniewska J, Tadele Z, Kubes M, Covanová M, Dhonukshe P, Skupa P, Benková E, Perry L, Krecek P, Lee OR, Fink GR, Geisler M, Murphy AS, Luschnig C, Zazímalová E, Friml J: PIN proteins 
perform a rate-limiting function in cellular auxin efflux. Science 2006, 3 I 2:9|4-8.

\section{FlOOOPrime} RECOMMENDED

6. Ulmasov T, Liu ZB, Hagen G, Guilfoyle T]: Composite structure of auxin response elements. Plant Cell 1995, 7:16 II-23.

7. Ulmasov T, Hagen G, Guilfoyle TJ: ARFI, a transcription factor that binds to auxin response elements. Science 1997, 276: $1865-8$

8. Ulmasov T, Murfett J, Hagen G, Guilfoyle TJ: Aux/IAA proteins repress expression of reporter genes containing natural and highly active synthetic auxin response elements. Plant Cell Online 1997, 9:1963-7|

9. Ruegger M, Dewey E, Gray WM, Hobbie L, Turner J, Estelle M: The TIRI protein of Arabidopsis functions in auxin response and is related to human SKP2 and yeast grrlp. Genes Dev 1998, I 2: 198-207.

10. Ulmasov T, Hagen G, Guilfoyle TJ: Dimerization and DNA binding of auxin response factors. Plant J Cell Mol Biol I999, I9:309-19.

II. Ulmasov T, Hagen G, Guilfoyle TJ: Activation and repression of transcription by auxin-response factors. Proc Natl Acad Sci USA 1999, 96:5844-9.

12. Gray WM, Kepinski S, Rouse D, Leyser O, Estelle M: Auxin regulates SCF(TIRI)-dependent degradation of AUX/IAA proteins. Nature 200I, 4I 4:27I-6.

\section{FlOOPrime}

\section{RECOMMENDED}

13. Dharmasiri N, Dharmasiri S, Estelle M: The F-box protein TIRI is an auxin receptor. Nature 2005, 435:44I-5.

\section{FlOOOPrime}

\section{RECOMMENDED}

14. Kepinski S, Leyser O: The Arabidopsis F-box protein TIRI is an auxin receptor. Nature 2005, 435:446-5I.

\section{FlOOOPrime} RECOMMENDED

I5. Calderon-Villalobos LI, Tan X, Zheng N, Estelle M: Auxin perceptionstructural insights. Cold Spring Harb Perspect Biol 2010, 2: a005546.

16. Havens KA, Guseman JM, Jang SS, Pierre-Jerome E, Bolten N, Klavins E, Nemhauser JL: A synthetic approach reveals extensive tunability of auxin signaling. Plant Physiol 2012, 160: 135-42

17. Calderón Villalobos LIA, Lee S, De Oliveira C, Ivetac A, Brandt W, Armitage L, Sheard LB, Tan X, Parry G, Mao H, Zheng N, Napier R, Kepinski S, Estelle M: A combinatorial TIRI/AFB-Aux/IAA coreceptor system for differential sensing of auxin. Nat Chem Biol 2012, 8:477-85

\section{FlOOOPrime} RECOMMENDED

18. Vernoux T, Brunoud G, Farcot E, Morin V, Daele HV den, Legrand J, Oliva M, Das P, Larrieu A, Wells D, Guédon Y, Armitage L, Picard F, Guyomarc'h S, Cellier C, Parry G, Koumproglou R, Doonan JH, Estelle M, Godin C, Kepinski S, Bennett M, De Veylder L, Traas J: The auxin signalling network translates dynamic input into robust patterning at the shoot apex. Mol Syst Biol 20I I, 7:508.

\section{FlOOOPrime}

\section{RECOMMENDED}

19. Shimizu-Mitao Y, Kakimoto T: Auxin Sensitivities of All Arabidopsis Aux/IAAs for Degradation in the Presence of Every TIRI/AFB. Plant Cell Physiol 20|4, 55:|450-9.

20. Pierre-Jerome E, Moss BL, Nemhauser JL: Tuning the auxin transcriptional response. J Exp Bot 2013, 64:2557-63.
21. Peer WA: From perception to attenuation: auxin signalling and responses. Curr Opin Plant Biol 2013, 16:56I-8.

22. Luschnig C, Vert G: The dynamics of plant plasma membrane proteins: PINs and beyond. Dev Camb Engl. 20I4 Aug:I4I(I5):2924-38.

23. Tivendale ND, Ross JJ, Cohen JD: The shifting paradigms of auxin biosynthesis. Trends Plant Sci 2014, 19:44-5I.

24. Wang R, Estelle M: Diversity and specificity: auxin perception and signaling through the TIRI/AFB pathway. Curr Opin Plant Biol 2014, 2 I C:51-8.

25. Boer DR, Freire-Rios A, van den Berg WAM, Saaki T, Manfield IW Kepinski S, López-Vidrieo I, Franco-Zorrilla JM, de Vries SC, Solano R, Weijers D, Coll M: Structural Basis for DNA Binding Specificity by the Auxin-Dependent ARF Transcription Factors. Cell 2014, I56:577-89.

FlOOOPrime

26. Korasick DA, Westfall CS, Lee SG, Nanao MH, Dumas R, Hagen G, Guilfoyle TJ, Jez JM, Strader LC: Molecular basis for AUXIN RESPONSE FACTOR protein interaction and the control of auxin response repression. Proc Natl Acad Sci 2014, I I I: 5427-32.

\section{FlOOOPrime}

27. Nanao MH, Vinos-Poyo T, Brunoud G, Thévenon E, Mazzoleni M, Mast D, Lainé S, Wang S, Hagen G, Li H, Guilfoyle T], Parcy F, Vernoux T, Dumas R: Structural basis for oligomerization of auxin transcriptional regulators. Nat Commun 2014, 5:36I7.

\section{FlOOOPrime} RECOMMENDED

28. Pierre-Jerome E, Jang SS, Havens KA, Nemhauser JL, Klavins E: Recapitulation of the forward nuclear auxin response pathway in yeast. Proc Natl Acad Sci 20 I4, I I I:9407- I 2.

29. Szemenyei $H$, Hannon M, Long JA: TOPLESS mediates auxindependent transcriptional repression during Arabidopsis embryogenesis. Science 2008, 3 I 9: | 384-6.

\section{FlOOOPrime}

30. Parry G, Calderon-Villalobos LI, Prigge M, Peret B, Dharmasiri S, Itoh H, Lechner E, Gray WM, Bennett M, Estelle M: Complex regulation of the TIRI/AFB family of auxin receptors. Proc Natl Acad Sci 2009, 106:22540-5.

31. Overvoorde PJ, Okushima Y, Alonso JM, Chan A, Chang C, Ecker JR, Hughes B, Liu A, Onodera C, Quach H, Smith A, Yu G, Theologis A Functional Genomic Analysis of the AUXIN/INDOLE-3. ACETIC ACID Gene Family Members in Arabidopsis thaliana. Plant Cell Online 2005, I 7:3282-300.

\section{FIOOOPrime
RECOMMENDED}

32. Remington DL, Vision TJ, Guilfoyle TJ, Reed JW: Contrasting modes of diversification in the Aux/IAA and ARF gene families. Plant Physiol 2004, I35: I738-52.

33. Rademacher $\mathrm{EH}$, Möller B, Lokerse AS, Llavata-Peris $\mathrm{Cl}$, van den Berg W, Weijers D: A cellular expression map of the Arabidopsis AUXIN RESPONSE FACTOR gene family. Plant J 201 I, 68:597-606

FlOOOPrime

34. Guilfoyle TJ, Hagen G: Getting a grasp on domain III/IV responsible for Auxin Response Factor-IAA protein interactions. Plant Sci 2012, 190:82-8.

\section{FlOOOPrime}

\section{RECOMMENDED}

35. Guilfoyle TJ, Ulmasov T, Hagen G: The ARF family of transcription factors and their role in plant hormone-responsive transcription. Cell Mol Life Sci CMLS I998, 54:619-27. 
36. Swaminathan $K$, Peterson K, Jack T: The plant B3 superfamily. Trends Plant Sci 2008, 13:647-55.

37. Tiwari SB, Hagen G, Guilfoyle $\mathrm{T}$ : The roles of auxin response factor domains in auxin-responsive transcription. Plant Cell 2003, I5:533-43.

38. Finet C, Berne-Dedieu A, Scutt CP, Marlétaz F: Evolution of the ARF Gene Family in Land Plants: Old Domains, New Tricks. Mol Biol Evol 2013, 30:45-56.

39. Adams-Cioaba MA, Li Z, Tempel W, Guo Y, Bian C, Li Y, Lam R, Min J: Crystal structures of the Tudor domains of human PHF20 reveal novel structural variations on the Royal Family of proteins. FEBS Lett 2012, 586:859-65.

40. Weiste C, Dröge-Laser W: The Arabidopsis transcription factor bZIPII activates auxin-mediated transcription by recruiting the histone acetylation machinery. Nat Commun 2014, 5:3883.

\section{FlOOOPrime
RECOMMENDED}

41. Nguyen HN, Kim JH, Jeong CY, Hong S-W, Lee H: Inhibition of histone deacetylation alters Arabidopsis root growth in response to auxin via PINI degradation. Plant Cell Rep 2013, 32:1625-36.

\section{FlOOOPrime}

\section{RECOMMENDED}

42. Anzola JM, Sieberer T, Ortbauer M, Butt H, Korbei B, Weinhofer I, Müllner AE, Luschnig C: Putative Arabidopsis Transcriptional Adaptor Protein (PROPORZI) is required to modulate histone acetylation in response to auxin. Proc Natl Acad Sci 2010, 107: 10308-13.

\section{FlOOOPrime}

RECOMMENDED

43. Manzano C, Ramirez-Parra E, Casimiro I, Otero S, Desvoyes B, De Rybel B, Beeckman T, Casero P, Gutierrez C, C Del Pozo J: Auxin and epigenetic regulation of SKP2B, an F-box that represses lateral root formation. Plant Physiol 2012, 160:749-62.

\section{FlOOOPrime \\ RECOMMENDED}

44. Chapman EJ, Estelle M: Mechanism of auxin-regulated gene expression in plants. Annu Rev Genet 2009, 43:265-85.

45. Shin R, Burch AY, Huppert KA, Tiwari SB, Murphy AS, Guilfoyle T], Schachtman DP: The Arabidopsis transcription factor MYB77 modulates auxin signal transduction. Plant Cell 2007, I9: 2440-53.

\section{FlOOOPrime \\ RECOMMENDED}

46. Varaud E, Brioudes F, Szécsi J, Leroux J, Brown S, PerrotRechenmann C, Bendahmane M: AUXIN RESPONSE FACTOR8 regulates Arabidopsis petal growth by interacting with the bHLH transcription factor BIGPETALp. Plant Cell 20II, 23:973-83.

\section{FlOOOPrime
RECOMMENDED}

47. Oh E, Zhu J-Y, Bai M-Y, Arenhart RA, Sun Y, Wang Z-Y: Cell elongation is regulated through a central circuit of interacting transcription factors in the Arabidopsis hypocotyl. elife 20I4, 3.

\section{FlOOOPrime
RECOMMENDED}

48. Kim J, Harter K, Theologis A: Protein-protein interactions among the Aux/IAA proteins. Proc Natl Acad Sci 1997, 94: II786-9|

49. Rinaldi MA, Liu J, Enders TA, Bartel B, Strader LC: A gain-offunction mutation in IAAI6 confers reduced responses to auxin and abscisic acid and impedes plant growth and fertility. Plant Mol Biol 2012, 79:359-73.

\section{FlOOOPrime
RECOMMENDED}

50. Sullivan AM, Arsovski AA, Lempe J, Bubb KL, Weirauch MT, Sabo PJ, Sandstrom R, Thurman RE, Neph S, Reynolds AP, Stergachis $A B$, Vernot $B$, Johnson AK, Haugen E, Sullivan ST, Thompson A, Neri FV 3rd, Weaver M, Diegel M, Mnaimneh S, Yang A, Hughes TR, Nemhauser JL, Queitsch C, Stamatoyannopoulos JA: Mapping and Dynamics of Regulatory DNA and Transcription Factor Networks in A. thaliana. Cell Rep 2014, 8:2015-30.

5I. Godoy M, Franco-Zorrilla JM, Pérez-Pérez J, Oliveros JC, Lorenzo O, Solano R: Improved protein-binding microarrays for the identification of DNA-binding specificities of transcription factors. Plant J Cell Mol Biol 201 I, 66:700-II.

\section{FlOOOPrime
RECOMMENDED}

52. Nishimura K, Fukagawa T, Takisawa H, Kakimoto T, Kanemaki M: An auxin-based degron system for the rapid depletion of proteins in nonplant cells. Nat Methods 2009, 6:917-22.

\section{FlOOOPrime}

RECOMMENDED

53. Deal RB, Henikoff S: The INTACT method for cell type-specific gene expression and chromatin profiling in Arabidopsis thaliana. Nat Protoc 201 I, 6:56-68.

\section{FlOOOPrime}

RECOMMENDED

54. Zhang X, Yazaki J, Sundaresan A, Cokus S, Chan SW-L, Chen H, Henderson IR, Shinn P, Pellegrini M, Jacobsen SE, Ecker JR.: Genomewide High-Resolution Mapping and Functional Analysis of DNA Methylation in Arabidopsis. Cell 2006, I 26: I 189-20I.

\section{FlOOOPrime
RECOMMENDED}

55. Lewis DR, Olex AL, Lundy SR, Turkett WH, Fetrow JS, Muday GK: A Kinetic Analysis of the Auxin Transcriptome Reveals Cell Wall Remodeling Proteins That Modulate Lateral Root Development in Arabidopsis. Plant Cell Online 2013, 25:3329-46.

\section{FlOOOPrime}

\section{RECOMMENDED}

56. Rensing SA, Lang D, Zimmer AD, Terry A, Salamov A, Shapiro H, Nishiyama T, Perroud PF, Lindquist EA, Kamisugi Y, Tanahashi T, Sakakibara K, Fujita T, Oishi K, Shin-I T, Kuroki Y, Toyoda A, Suzuki Y, Hashimoto S, Yamaguchi K, Sugano S, Kohara Y, Fujiyama A, Anterola A, Aoki S, Ashton N, Barbazuk WB, Barker E, Bennetzen JL, Blankenship R, et al:: The Physcomitrella Genome Reveals Evolutionary Insights into the Conquest of Land by Plants. Science 2008, 319:64-9.

\section{FlOOOPrime

RECOMMENDED

57. Prigge MJ, Lavy M, Ashton NW, Estelle M: Physcomitrella patens Auxin-Resistant Mutants Affect Conserved Elements of an Auxin-Signaling Pathway. Curr Biol 2010, 20:1907-I2.

\section{FlOOOPrime
RECOMMENDED}

58. Bowman JL, Floyd SK, Sakakibara K: Green Genes-Comparative Genomics of the Green Branch of Life. Cell 2007, I 29:229-34.

59. Ishizaki K, Nonomura M, Kato H, Yamato KT, Kohchi T: Visualization of auxin-mediated transcriptional activation using a common auxin-responsive reporter system in the liverwort Marchantia polymorpha. J Plant Res 2012, I 25:643-5I.

60. Sugano SS, Shirakawa M, Takagi J, Matsuda Y, Shimada T, HaraNishimura I, Kohchi T: CRISPR/Cas9-Mediated Targeted Mutagenesis in the Liverwort Marchantia polymorpha L. Plant Cell Physiol 2014, 55:475-8I.

61. Cove DJ, Perroud P-F, Charron AJ, McDaniel SF, Khandelwal A, Quatrano RS: The Moss Physcomitrella patens: A Novel Model 
System for Plant Development and Genomic Studies. Cold Spring Harb Protoc 2009, 2009:pdb.emol I5.

\section{FlOOOPrime}

62. Ishizaki K, Johzuka-Hisatomi $Y$, Ishida S, lida S, Kohchi T: Homologous recombination-mediated gene targeting in the liverwort Marchantia polymorpha L. Sci Rep 2013, 3:1532.

\section{FlOOOPrime} RECOMMENDED

63. Tromas A, Paque S, Stierlé V, Quettier A-L, Muller P, Lechner E, Genschik P, Perrot-Rechenmann C: Auxin-binding protein I is a negative regulator of the SCF(TIRI/AFB) pathway. Nat Commun 2013, 4:2496.

\section{FlOOOPrime}

64. Xu T, Dai N, Chen J, Nagawa S, Cao M, Li H, Zhou Z, Chen X, De Rycke R, Rakusová H, Wang W, Jones AM, Friml J, Patterson SE, Bleecker AB, Yang Z: Cell Surface ABPI-TMK Auxin-Sensing Complex Activates ROP GTPase Signaling. Science 2014, 343: $1025-8$.

FlOOOPrime

RECOMMENDED 